\title{
Job stress management protocol using a merge between cognitive-behavioral techniques and ergonomic tools
}

\author{
Elaine Viola ${ }^{\mathrm{a}, *}$, Mario Cesar Vidal ${ }^{\mathrm{b}}$ \\ ${ }^{a}$ Ergo\&Plus Consulting Services, Av. Americas, 2901, sl. 217, CEP 22631002, Rio de Janeiro, RJ, Brazil \\ ${ }^{\mathrm{b}}$ Ergonomic Unit, Production Engineering Program, Federal University of Rio de Janeiro. Av. Horacio Macedo \\ 203, Centro de Tecnologia. Sala G-207, CEP 21941-914, Rio de Janeiro, Brazil
}

\begin{abstract}
This paper presents a protocol for work distress assessment. Work distress is defined as a merge between nonergonomic related aspects, in tasks or environment, and adversely conditions perceived for a worker, in a certain work situation. This frame requires an approach that can treat individuals and organizational factors in the same way, at the same time. For this, we elaborate a psycho-ergonomics method, associating concepts and practices from cognitive-behavioral techniques and work ergonomic analysis, which we named CEWAT - Cognitive-Behavioral Work Analysis Technique. This paper presents CEWAT's foundations and structure, in steps. An application to a complex and dangerous system illustrates its benefits in the ergonomics action.
\end{abstract}

Keywords: Stress, ergonomics, cognitive-behavioral techniques, participatory design.

\section{Prologue}

The aim of this paper is to present a job stress management approach by combining techniques targeting subjective and objective dimensions of work. Its main goal is to encourage a reflection in groups who share a work activity, with the purpose of make positive transformations in work environment, work systems and workers interrelationships. The specific original context of this method derived from complex and dangerous activities. Nevertheless, it aims to be more wide, including current job analysis and transformation in several types of activities.

Job stress, here, is conceived as a phenomenon that occurs in the field of the interactions between humans' subjective feeling of working and the sociotechnical system (technologies, environment and organizational rules) in which they objectively work [1], [2]. For our purposes, job stress is defined as a state of anxiety that arises when there are discrepancies between objective job demands and individual's perception of capabilities, in either direction (i.e., overload- or under load) [3]. With Wisner [4] we assume that this anxiety lays over objective basis.

Job stress management has been viewed by different approaches. Basically, it is possible to distinguish two major groups [5]: the psychological approaches, which privileges the individual characteristics, as factors of stress (personality characteristics and personal styles of perception), and the organizational approaches, focusing work environment and organizational methods. Our appreciation and evaluation of these positions, through our experience in ergonomics practices, let us to assume that job stress depends on a singular join of these two concepts. This combination involves situated work conditions and human felt vulnerabilities. Henceforth, it is named as situated distress scenery.

Thus, situated distress scenery has an objective basis: it is supposed to appear when workers are trying to do their tasks without success. The psychological dimension arises from this lack of success; whatever they may do, they not found a way to do it as well. Ergonomic evaluation should identify work situations

\footnotetext{
*Corresponding author. Email: esviola3@hotmail.com
} 
patterns in which situated distress represents a risk for health and productivity. Furthermore, the psychological approach should help workers to cope with stress, creating new ways to do these tasks, to make pertinent decisions, and to fit their operative communications.

The central assumption is that job stress can be managed using a psycho-ergonomic method, merging behavioral-cognitive methods [6] [7] and ergonomic evaluation tools [8] [9]. The worker-centered approach provided by an ergonomic modeling of a situation is counterbalanced by the cognitive-behavioral techniques, focusing human needs and environment conditions' adjustment. These are foundations that allow us the integration of the treatment of individual needs and organizational demands, inside situated distress scenery. For practical uses, we called this approach CEWAT - Cognitive Ergonomic WorkAnalysis Technique.

\section{Frame}

CEWAT is oriented by the generic ergonomic premise that it is a conceptual distance between prescribed and current work activity [10]. In order to reduce such conceptual distance, workers make use of a set of alternative procedures - the regulations - to cope with the actual state of the work system. These procedures derive from a need to compensate problems or a constraint that occurs in the course of action. Their origin is the perception workers have about their current capabilities, as well as the work system's variability status [11].

Even considering that such regulations could be generally healthy in its own nature, it is possible that they may cause distress-related effects, in the human dimension, and losses and accidents, in the system performance. Figure 1 shows the general frame of CEWAT.

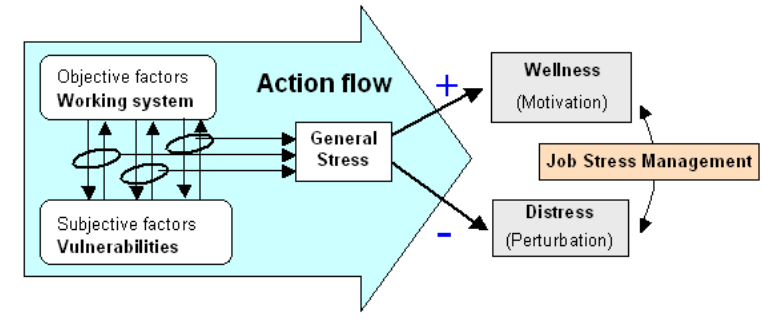

Figure 1: CEWAT general frame

This frame considers that a given working system could be sufficiently modeled as a full objective re- presentation of the current situation. In the same way, conversional action data gathered during ergonomic modeling can be taken as materials for cognitivebehavioral approach. The general stress screening obtained is evaluated as positive or negative consequences, occasioning its interpretation as motivating factor (to be promoted) and/or as perturbation factors (to be avoided)

Still, vulnerabilities are much more susceptible of introspective effects. In this sense, we can dispose of an acceptable operative model of the current situation, having no enough material reports of their related vulnerabilities. This brings us an important methodological step: cognitive-behavioral methods are, now, employed to promote their emergence face to the situated work condition, configured by means of the ergonomic operative modeling.

Functionally, CEWAT appears as a protocol divided into three steps: Global analysis, Practices, and Results. These steps are subdivided into six stages, which have specifics and complementary goals. Each goal is supposed to be attempt by mean of a specific tool. Table 1 shows a scheme of the entire tool's steps.

\section{The first step: Global analysis}

The first step, Global analysis, is focused on the identification and specification of the demands, and contains three stages: a Prepare, a Questionnaire, and a Conversational action.

Prepare step is divided into two goals - contracting and motivation. First of all, the contract stage employs request analysis as a tool. It is a dialogic tool based upon the counterpoint between the requesting person's enunciations and the ergonomist rebuilding proposals, in the intervention perspective [12]. This goal issues a menu of managerial demands. Then, by a structured engagement meeting [13], these plans are presented to all members of the work team. The sub goal here is to include their demands, and, consequently, motivate each one to the intervention. This step, as a whole, screens the effective situated demand, by combining the managerial and the work team one's.

Moreover, we have the inquiry stage, which has two goals: the application and the feedback. To apply the inquiry, the ergonomist, focusing the demand, elaborates a targeted questionnaire [14]. This tool aims to give rise the opportunity for the workers to express themselves in an anonymous way. The gathered materials are exposed and validated during a 
feedback session [13]. In the participatory sense, the inquiry cannot be achieved without this stage. This feedback session is not only a presentation of a plot of gathered data. It is the link for the beginning of a shared construction of knowledge about the situated distress and its impacts in the work activity. In such context, the ergonomist plays two iterant roles: as a facilitator, by stimulating identifications and interpretations of distress ' factors, and as an ergonomist, by consolidating the activity analysis.

Finally, the conversational action stage is performed. It is issued from the feedback, and has two goals: the Free Group Interview - FGI [8] and the Cognitive Mapping [15] [16] [17].

During FGI, cognitive-behavioral tools [18] are applied to the work team in a free group interview, featured as a cognitive group dynamics, in which the team is previously trained in some rules for be attentive and opened for hear other's points of view. The lead question is: "Tell us how you perform your tasks". After this, the ergonomics and the team lead- er will have a meeting focused on a coach. In it, the leader will have the opportunity to talk about, to reflect and to make up their mind about the different perceptions he had heard at the meeting. FGI is, thus, the first step in the search for a consensus about possible solutions for the demands, involving organizational and individuals' needs.

In the next stage - the cognitive mapping - it's time to workers see, in a practical way, the difference of the activity they think they do and what they really do. For this, we create a specific dynamic that consists of asking workers to appoint the tasks they do, detailed in steps, in the left column of a blackboard or similar. On the right side, the ergonomist appoints the list of common troubles which had been listed for them in the free group interview, before. At the final and main part of the dynamic, workers are encouraged to link problems (right side) and tasks steps (left side), searching for the causes and the solutions for them.

Table 1

The CEWAT's steps, stages, goals and related tools.

\begin{tabular}{|c|c|c|c|}
\hline Step & Stage & Goal & Tools \\
\hline \multirow{6}{*}{$\begin{array}{l}\text { Global analysis: } \\
\text { Goals and investigation of } \\
\text { the needs }\end{array}$} & \multirow[t]{2}{*}{ Prepare } & Contract & Request analysis \\
\hline & & Motivation & Engagement meeting \\
\hline & \multirow[t]{2}{*}{ Inquiry } & Application & Targeted questionnaire \\
\hline & & Feedbacking & R\&V settings \\
\hline & \multirow[t]{2}{*}{ Conversation action } & Free Group Interview & Cognitive-behavioral tools \\
\hline & & Cognitive mapping & Cognitive-behavioral tools \\
\hline \multirow{4}{*}{$\begin{array}{l}\text { Practices: } \\
\text { Treatment of the situated } \\
\text { distress aspects }\end{array}$} & \multirow[t]{2}{*}{ Ergonomic appreciation } & Work analysis & Ergonomics methods \\
\hline & & Conceptualization & Ergonomic modeling \\
\hline & \multirow[t]{2}{*}{ Participatory design } & Validation & R\&V settings \\
\hline & & Adjustments & R\&V settings \\
\hline \multirow{2}{*}{$\begin{array}{l}\text { Issues: } \\
\text { Near Future Directions }\end{array}$} & Results & Presentation & R\&V settings \\
\hline & Improvements & Implementation strategy & Change management tools \\
\hline
\end{tabular}

\section{Practices: The first step of changing:}

The goal of the practices' step is to put on action better work procedures, in order to construct the positive changes yet planned. Practices begin by training people to observe themselves when working. In that, team leader, ergonomic and workers learn some ergonomics methods for work analysis in real work situations. When the points that need changes arise in real situations, it's time to begin assisted changes in the routine, modeling, with ergonomic tools, another protocol for the activity. The workers apply the solutions previously accorded, transforming the work environment, procedures and relationships. This is the moment for change paradigms too, and for this, CBT tools could be associated to the ergonomic approach. In CBT, there are many methods and ways focused on change our old thinking patterns and habits, some tools that can be adapted to be used to follow change evolutions in real work situations [18] [19], for example, a table when workers can write down relations between problems and tasks steps, or a "conquest book", which objective is to sustain the 
group motivation. Writing and reading after, they can be more conscientiously about their capacities and difficulties, avoiding distortions of the memories. Techniques for goals construction and others are often employed, when it's necessary.

After many experiments in real work situations, the team is able to elaborate together a new participatory task design, based on the result of the last step. For this, the new protocol is tested, adjusted and validated for each activity step, employing Restitution \&Validation tools [13] [19].

\section{Issues: The second step of changes}

Finally, in the Issues step, near future directions are searched, as well as a strategy is outlined. The results of new task design are submitted to a follow up, and improvements are debated in these evaluations meetings. It's important to underline that situated work and situated stress are always changing with variability, so new propositions could require solutions adequate to other contexts.

\section{A case in an oil company}

This example is about an application of CEWAT in an oil company, at a plant, which will be transfer soon to a new workplace. The shared activity is the control of oil lines, operated by a team of seven workers and one supervisor. Their goal is a new design to be applied in a new workplace.

CEWAT was applied in five sessions. The main tools utilized are questionnaire, cognitive mapping, and emotional understanding. All of these tools are designed specifically for the present work situation. In the step of the questionnaire, interesting data was collected for discussion. As we can see in Figure 2, it could be observed that all the workers (100\%) reported that they need to employ much attention and memory ability in their work. Other question let us know that eighty per cent of workers need to do several tasks simultaneously in seventy per cent of their work time; concluding, only ten per cent have reported that was not in a continuous anxious state that does not end when work finishes.

After this feedback, the workers and supervisor began to discuss the situated distress and the consequences generated for these requirements. How is it possible to have security and wellness, when $80 \%$ of the workers have to do two or more tasks simultaneously? And when all of them need to pay attention and use memory abilities more than $70 \%$ of the time?
Remark that the questionnaire is used both as a data collection method and a strategy to create a cooperative dialogic context.

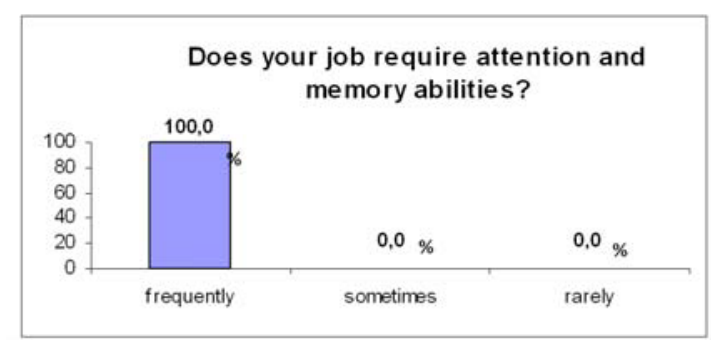

Figure 2 : An example of questionary result

During this discussion, the team leader is making an important exercise. Previously he was trained to listen with attention the operator's discussion. At the moment of the meeting, the ergonomics asks him to make some essential appointments as this:

-The subject that was discussed,

-The name of the worker that was talking,

-What emotion he perceived in the worker.

- His/her feelings or thoughts about it.

The ergonomics give the team leader a table like in Table 2, with questions in the first line and blank fields to fill. He asks him to fill the blanks with his observations. The second line shows us an example of his answers.

After the interview, the supervisor was encouraged to present their observations and notes to the ergonomist, and discuss his emotions and thoughts in private coach session. Some difficulties in work relationships are identified, and the ergonomist could elaborate for him a personal program to develop communicational skills.

At last, in other session, when the questionnaire and the conversation had generated a context of search for solutions, the ergonomist consider that there is the moment to apply the 'cognitive mapping', focused on the steps of the shared activities.

In it, the ergonomist open the meeting asking each work team's member to describe three or four most important tasks they do. Then, they were asked to link their tasks with the colleagues'. A blackboard is used for the appointments. When they marked in the map and visualized the relations between their tasks, it is supposed that workers will better understand the communication web that joins their activities, which generates distress. 
Table 2

Table to leader's coach with the ergonomist

\begin{tabular}{|l|l|l|l|l|}
\hline Emotive Sentences & $\begin{array}{l}\text { Mentioned } \\
\text { Subject }\end{array}$ & $\begin{array}{l}\text { Emotion perceived } \\
\text { by the inquired }\end{array}$ & His/her feelings & $\begin{array}{l}\text { Who } \\
\text { tioned this }\end{array}$ \\
\hline $\begin{array}{l}\text { - All the time I have to pay- } \\
\text { attention in the gas lines” } \\
\text { mental overload }\end{array}$ & Anxious, worried & $\begin{array}{l}\text { Why I can't transmit } \\
\text { enough support? I fell } \\
\text { frustrated }\end{array}$ & $\begin{array}{l}\text { operator } \\
\text { "Antonio' }\end{array}$ \\
\hline (to fill) & (to fill) & (to fill) & (to fill) & (to fill) \\
\hline (to fill) & (to fill) & (to fill) & (to fill) & (to fill) \\
\hline
\end{tabular}

The second step begins with a presentation of a list that contains the most common distressors in the activity of oil and gas operators that were pointed by them in the questionnaire and the interview. Each worker was asked to associate distressors and steps of their task; for example, 'to check parameters in a computer program' with 'exigencies of memory and concentration'.

The workers were encouraged either to associate a degree of intensity - for example, 8 , in a zero to ten likert scale. At the end of the intervention, the workers elaborate an organized way to see the shared activity and a plan of improvements, to apply later.

\section{Discussion}

Some assertive can be outlined:

- The CBT approach is focus-oriented, is short, and has a participative style. These attributes were essentials to CEWAT purposes, since they bring up agile driving of the protocol. This reveals an interesting subject: even the working system analyzed could not necessarily be a complex system, the ergonomist team should perform as an adaptive one. Hence agility is an essential request to any protocol for ergonomic intervention.

- The ergonomic intervention having stress as its main subject improved communications and better operational relationships. Indeed, this working quality characteristic was not provided by the protocol. It was obscured by present stress conditions and distress effect in the working team. One cannot promise to deliver such kind of results, but, on the other hand, it will be a serious mistake to avoid this uncontrolled issue. Even because they will not necessary to be an improvement.
- Positive organizational changes can be obtained by the connection of an ergonomics screening and a CBT approach. It shows that CEWAT protocol can be useful for different levels of ergonomic expertise within several organizational contexts. The exposed case, for instance, was centered in the leader appreciations and tacit knowledge elicitation. Well, a leader is supposed to be sensible to organizational matters, but the workers are too. The choice for the way to conduce the ergonomic action depends on the form that lead us to a better interaction between ergonomist, leader and the team.

- CEWAT requires a good handling of features, CBT and Ergonomic analysis. It requires also a medium level of participatory design expertise. Ipso facto, CEWAT is really not a quick protocol. The intention, here is more than communicate an issue for job stress management rather than to promote an easy-to-use protocol. It often requires an ergonomic team, rarely a single consulting person.

\section{Conclusion}

The merge of ergonomics methods and CBT tools, applied for job stress management, has become possible to exhibit effectiveness in promoting positive changes, with outcomes in work environment and individuals' wellness. Essentially, it solves some demands that are in the origin of the situated distress.

However, CEWAT needs some conditions to ensure its full success. The protocol was designed for groups not greater than fifteen members. These members also must have regular, face-to-face interaction, as well as commonality of purpose, task, or objective. Besides, the ergonomic approach can allow better contributions since the group has a task- 
oriented nature. In the psychological concern, this group should have an established level of interpersonal relationship. The protocol suggests and requires that the discussions emerge feelings and interactions, latent conflicts, competition sceneries, fears, and others unhealthy forms of relation-based psychological issues.

Such psycho-ergonomic approach could reveal not only organizational change results. It also presents some advantages for preventive managing job stress, aimed at improving performance effectiveness through cooperative, supportive relationships. The outcome should be a well-integrated work group, in which individuals give and receive needed support.

Moreover, the case showed that is not necessary the pre-existence of stress to apply and see the benefits of CEWAT. Stress is a life condition, and it is present in daily situations. In consequence, CEWAT provides a sustainable approach for organizational stress management.

Summarizing, we agree that there aren't pre existent factors, or pre existents standards for treat, cure or prevent stress consequences. Otherwise CEWAT show that there are ways to do it systematically, by launching each group must construct itself a solution. Techniques must only create conditions for dialog, for share purposes, wishes and feelings. Social construction as including workers and leaders indicates how it is possible to change, together, problems in opportunities to development. Even in job stress sceneries.

\section{References}

[1] Lazarus R. S., Folkman S. Stress, Appraisal And Coping. New York: Springer, 1984

[2] Shaw D., Ackermann F., Eden C. Approaches to Sharing Knowledge in Group Problem Structuring. Journal of the Operational Research Society. v. 54 n. 9, 2003.

[3] Selye H. Stress without Distress. Philadelphia: Lippincott Williams \& Wilkins Publisher, 1974.

[4] Wisner A. A Inteligência no Trabalho: textos selecionados de ergonomia. São Paulo: Editora Fundacentro, 1994.

[5] Murta, S. G. Programas de Manejo de Estresse Ocupacional: uma revisão sistemática da literatura. Revista Brasileira de Terapia Comportamental e Cognitiva. V. 7, n. 2, dez., 2005.

[6] Cooper, C.L. Handbook of Stress, medicine and health. Florida: CRC Press, 2nd edition, 2005.

[7] Knapp, P., Beck, A. T. Fundamentos, modelos conceituais, aplicações e pesquisa da terapia cognitiva. Rev. Bras. Psiquiatr. [online]. 2008, v. 30, suppl.2, pp. s54-s64. Disponível em

$<$ http://www.scielo.br/scielo.php?script $=$ sci arttext\&pid $=\mathrm{S} 15$ $16-44462008000600002 \& \operatorname{lng}=\mathrm{en} \& \mathrm{nrm}=\mathrm{iso}>$..Acesso em 8 Nov. 2008
[8] Vidal, M. C. , Bonfatti, R. J. - Conversational Action: an Ergonomic Approach to Interaction In: Grant P. - Rethinking communicative interaction Amsterdam : John Benjamin Publishing Company, 2003, p. 108-120

[9] Canas, J., Waerns, Y. Ergonomía Cognitiva: aspectos psicológicos de la interacción de las personas con la tecnología de la información. Madrid: Editoral Medica Panamericana, 2001

[10] Hendrick, H. W. Macroergonomics: an introduction to work system design. Santa Monica: HFES, 2000.

[11] Antoniazzi, A. S., Dell'Aglio, D. D., Bandeira, D. R. O Conceito de Coping: uma revisão teórica. Estud. psicol. [online] v. 3, n. 2,1998. Disponível em: $<$ http://www.scielo.br/scielo.php?script=sci_arttext\&pid=S14 13-294X1998000200006\&lng=en\&nrm=iso $>$. Acesso em 22 Set. 2009.

[12] Argyris, C.- Intervention Theory and Method: a behavioral science view, Addison-Wesley, USA, 1970.

[13] Daniellou, F. - La contruction sociale de et l'analyse du travail. in: Performances humaines et techniques, $\mathrm{n}^{\mathrm{o}}$ hors série, Toulouse, pp. 25 - 29, 1995.

[14] McMullin, R. Manual de Técnicas em Terapia Cognitiva. Porto Alegre: Artmed, 2005.

[15] Hoffman, R. R., Shadbolt, N. R., Buton, A. M., \& Klein, G. (1995). Eliciting knowledge from experts: A methodological analysis. Organizational Behavior and Human Design Processes, 62(2), 129-158.

[16] Shaw D., Ackermann F., Eden C. Approaches to Sharing Knowledge in Group Problem Structuring. Journal of the Operational Research Society. v. 54 n. 9, 2003.

[17] Bastos, A. V. B. Mapas Cognitivos e a Pesquisa Organizacional: explorando aspectos metodológicos. Estud. psicol. [online] v.7, n. Spe, 2002, Disponível em: $<$ http://www.scielo.br/scielo.php?script=sci_arttext\&pid= S1413-294X2002000300008\&lng=en\&nrm=iso>. Acesso em 2 out. 2009.

[18] Abreu, C.N., Roso, M. e colaboradores 2003, Psicoterapias Cognitiva e Construtivista: novas fronteiras da prática clínica. Porto Alegre, Artmed.

[19] Vidal M. C. - Guide to ergonomic work analysis. Rio de Janeiro, EVC, 2003 (in Portuguese).

[20] Leahy, R. Técnicas de Terapia Cognitiva: manual do terapeuta. Porto Alegre: Artmed, 2006. 